\title{
Comparison of breast-conserving therapy with mastectomy for treatment of early breast cancer in community hospitals
}

\author{
A. C. Voogd*, H. W. Nab*†, M. A. Crommelin† $\neq$, L. H. van der Heijden*, \\ H. M. Kluck $\S$ and J. W. W. Coebergh*+† \\ ${ }^{*}$ Comprehensive Cancer Centre South, P.O. Box 231, 5600 AE, Eindhoven, The Netherlands, \\ $\dagger$ Department of Epidemiology \& Biostatistics, Erasmus University Medical School, P.O. Box 1738, \\ 3000 DR, Rorterdam, The Netherlands, $₫$ Department of Radiotherapy, Catharina Hospital, \\ P.O. Box 1350, 5602 ZA, Eindhoven, The Netherlands, §Department of Surgery, St. Joseph Hospital, \\ De Run 4600, 5504 DB, Veldhoven, The Netherlands, \|Regional Breast Cancer Study Group, Eindhoven, \\ The Netherlands
}

\begin{abstract}
Although the results of clinical trials support breast-conserving therapy as a replacement for mastectomy in early breast cancer, the question remains whether these results apply in routine clinical practice. In the present analysis the breast cancer-specific survival and recurrence-free survival of 464 consecutive patients with breast tumours $\leq 3 \mathrm{~cm}$ across undergoing breast-conserving therapy were compared with a group of 459 patients with similar extent of disease and period of diagnosis undergoing mastectomy. All patients were treated in community hospitals in the south-eastern Netherlands. Median follow-up of both treatment groups was 6.2 years. After adjustment for the prognostic effects of age, tumour size, axillary nodal status and adjuvant systemic therapy, neither breast cancer-specific survival nor recurrence-free survival differed significantly between the breast-conserving therapy group and the mastectomy group. This finding indicates that in routine clinical practice breast-conserving therapy may be as effective as mastectomy.
\end{abstract}

Key words: breast cancer; breast-conserving therapy; mastectomy.

Introduction

The efficacy of breast-conserving therapy (BCT) and mastectomy in early breast cancer has been compared in several randomized clinical trials carried out during the seventies and early eighties. ${ }^{1-3}$ All trials yielded similar survival rates for the two types of primary treatment. At subsequent consensus meetings and in various national, regional and institutional guidelines for treatment, BCT has been considered an appropriate method of primary therapy for the majority of women with stage I or II breast cancer. Nonetheless, substantial variation still exists in the proportion of women receiving BCT between hospitals and across regions. ${ }^{4-7}$ In addition, especially older women have been reported to be less likely to receive $B C T .^{6-10}$ This may reflect the current uncertainties about selection criteria and the effectiveness of $\mathrm{BCT}$ in routine clinical practice.

In the south-eastern Netherlands, BCT was introduced into the treatment guidelines of the regional Breast Cancer Study Group in 1981. The area is exclusively served by community hospitals and one department of radiotherapy and characterized by a high and increasing incidénce of early breast cancer." Until 1991, the use of BCT increased gradually, although showing considerable variation between hospitals and being smaller in the elderly. ${ }^{12}$ In a previous analysis of all patients treated with BCT between 1981 and 1987, survival and recurrence rates appeared to be comparable to those reported in literature. ${ }^{13}$ In the current study we compared the breast cancer-specific survival and recurrence-free survival rate for BCT and mastectomy after a median follow-up of 6 years.

\section{Patients and methods}

Data were obtained from the population-based Eindhoven Cancer Registry, which serves a population of almost one million inhabitants in the south-eastern part of the Netherlands ( $7 \%$ of the Dutch population). ${ }^{14}$ Data were collected by the cancer registry from copies of the pathologist's reports and from the medical records of eight community hospitals and the regional department of radiotherapy. Between 1981 and 1987,482 patients with an invasive breast tumour $\leq 3 \mathrm{~cm}$ in diameter and post-surgical axillary nodal status $\mathrm{N}_{0}$ or $\mathrm{N}_{1}$ underwent BCT. During the same period 872 patients with breast cancer of the same stage had undergone modified radical mastectomy and from this group 500 patients were randomly selected: 150 from the period 1981-3 and 350 from the period 1984-7.

At the departments of surgery and the department of radiotherapy all medical records were screened for clinical events, including the site and date of any recurrence (local, regional or distant) and the date of death, up to June 1992. Information on the vital status was obtained from general 
Table 1. Characteristics of patients according to primary treatment

\begin{tabular}{|c|c|c|}
\hline \multirow[b]{2}{*}{ Variable } & \multicolumn{2}{|c|}{ Primary treatment } \\
\hline & $\begin{array}{c}\text { BCT } \\
(n=464)\end{array}$ & $\begin{array}{l}\text { Mastectomy } \\
(n=457)\end{array}$ \\
\hline \multicolumn{3}{|c|}{ Follow-up interval (years) } \\
\hline Mean & 6.2 & 6.2 \\
\hline Range & $0.8-11.1$ & $0.4-11.2$ \\
\hline \multicolumn{3}{|l|}{ Age (years) } \\
\hline$\leq 45$ & $144(31 \%)$ & $79(17 \%)$ \\
\hline $46-65$ & $251(54 \%)$ & $228(50 \%)$ \\
\hline$\geq 66$ & $69(15 \%)$ & $150(33 \%)$ \\
\hline Mean & 51.6 & 58.3 \\
\hline Range & $27-85$ & $26-87$ \\
\hline \multicolumn{3}{|c|}{ Period of primary treatment } \\
\hline $1981-3$ & $127(27 \%)$ & $124(27 \%)$ \\
\hline 1984-7 & $337(73 \%)$ & $323(73 \%)$ \\
\hline \multicolumn{3}{|l|}{ Tumour size $(\mathrm{cm})$} \\
\hline$\leq 2.0$ & $380(82 \%)$ & $259(57 \%)$ \\
\hline $2.1-3.0$ & $84(18 \%)$ & $198(43 \%)$ \\
\hline \multicolumn{3}{|l|}{ Nodal status } \\
\hline $\mathrm{pN}_{0}$ & $346(75 \%)$ & $293(64 \%)$ \\
\hline $\mathrm{pN}_{1}$ & $118(25 \%)$ & $164(36 \%)$ \\
\hline \multicolumn{3}{|c|}{$\begin{array}{l}\text { Adjuvant systemic therapy (Adj) } \\
\text { according to nodal status }\end{array}$} \\
\hline $\mathrm{pN}_{0}$ without $\mathrm{Adj}$ & $342(99 \%)$ & $288(98 \%)$ \\
\hline $\mathrm{pN}_{0}$ with Adj & $4(1 \%)$ & $5(21 / 1)$ \\
\hline $\mathrm{pN}$, without $\mathrm{Adj}$ & $44(37 \%)$ & $85(52 \%)$ \\
\hline $\mathrm{pN}_{0}$ with Adj & $74(63 \%)$ & $79(48 \%)$ \\
\hline
\end{tabular}

practitioners and municipal registries. Four patients undergoing mastectomy and one patient undergoing BCT could not be traced after the date of primary treatment. Another 39 and 17 patients were excluded from the mastectomy group and the BCT group respectively: 25 and 10 with a previous breast tumour, nine and six with another previous malignancy and five and one respectively with synchronous bilateral breast cancer. Ultimately 921 patients were available for analysis, 464 with $\mathrm{BCT}$ and 457 with modified radical mastectomy (Table 1 ).

Guidelines for BCT and modified radical mastectomy were drawn up in 1981 by the regional Breast Cancer Study Group and adapted in 1983. Initially, all breast cancer patients with tumours $\leq 2 \mathrm{~cm}$ across at mammography were considered candidates for BCT, but in $19843 \mathrm{~cm}$ became the limit. Patients with relatively small breasts, diffuse microcalcifications on the mammogram, a tumour fixed to the muscles, or multiple breast tumours were supposed to undergo mastectomy. From 1981 until 1987 the proportion of patients with a tumour $\leq 2 \mathrm{~cm}$ who had BCT increased from $21 \%$ to $46 \%$. The proportion of patients with tumours of $2-3 \mathrm{~cm}$ having BCT increased from less than $10 \%$ to $28 \%$.

According to the guidelines, breast-conserving surgery involved a wide local excision of the tumour with an attempted margin of at least $1 \mathrm{~cm}$ of healthy tissue. Mastectomy was supposed to be of the modified radical type, according to the method of Patey or Madden. Both types of surgery included axillary dissection. All patients who underwent breast-conserving surgery received total breast irradiation, usually $50 \mathrm{~Gy}$ within 5 weeks with an additional booster dose of 14-15 Gy to the tumour bed. Of the mastectomy patients $52 \%$ underwent irradiation.
Adjuvant systemic therapy was recommended only for axillary node-positive patients, regardless of the type of surgery. Chemotherapy (six cycles of cyclophosphamide, methotrexate and fluorouracil) was indicated for premenopausal patients and hormonal therapy (tamoxifen) for post-menopausal patients with oestrogen receptor-positive tumours.

Breast cancer-specific survival and recurrence-free survival, calculated from the date of BCT or mastectomy, were used as endpoints in this study. Breast cancer-specific survival was based on death due to, or in the presence of, distant recurrence. Patients dying without distant recurrence and patients still living at the date of the last follow-up were considered as censored. To determine recurrence-free survival each first recurrence (local, regional or distant) was scored as an event. Patients without tumour recurrence were considered withdrawn alive at the date of last follow-up or death. Local recurrence was defined as pathologically confirmed tumour growth in the preserved breast after BCT or in the chest wall after mastectomy, regional recurrence as pathologically confirmed tumour growth in lymph nodes in the ipsilateral axilla and/or infraclavicular fossa and/or parasternal lymph nodes; clinically confirmed relapse of breast cancer in any other location was considered as distant recurrence.

The life-table method was used to perform the survival analysis. ${ }^{15}$ To compare breast cancer-specific and recurrencefree survival in the BCT group and the mastectomy group the Cox proportional hazards model was used to adjust for the influence of the following prognostic factors: age, tumour size, axillary nodal status and adjuvant systemic therapy. ${ }^{16}$ The resulting model parameters were converted to relative risks.

\section{Results}

The median follow-up time was 6.2 years for both treatment groups (Table 1). Between the BCT group and the mastectomy group there were significant differences in age, tumour size, and nodal status $\left(\chi^{2}: P<0.001\right)$ (Table 1 ). Nodepositive patients in the BCT group were more likely to receive adjuvant systemic therapy $\left(\gamma^{2}: P<0.001\right): 63 \%$ of the node-positive patients in the BCT group received any form of adjuvant systemic therapy vs $48 \%$ in the mastectomy group (Table 1). Of all node-negative patients only nine received adjuvant systemic therapy.

A total of 198 patients died (21\%), 84 after BCT and 114 after mastectomy. Of all deaths 125 were breast cancerrelated: 60 after BCT and 65 after mastectomy. At 7 years the breast cancer-specific survival rates were $84 \%(95 \% \mathrm{CI}$ : 80-88) for BCT patients and $86 \%(95 \% \mathrm{CI}: 82-90)$ for those treated with mastectomy (Fig. I). Adjuvant systemic therapy and nodal status were combined to one variable consisting of three categories when included into the multivariate Cox model. After adjustment for the potentially confounding effect of age, tumour size and the combined variable of nodal status and adjuvant systemic therapy, the relative risk for death due to breast cancer for the BCT group compared to the mastectomy group was $1.09(P=0.67)$ (Table 2). Node-positive patients with adjuvant systemic therapy were 
found to have a reduced relative risk of dying from breast cancer compared with node-positive patients without systemic therapy ( $\mathrm{RR}=0.48 ; P=0.006$ ) (Table 2).

Tumour recurrence was detected in $104 \mathrm{BCT}$ patients and in 119 mastectomy patients (Table 3). At 7 years, the actuarial recurrence-free survival rates were $77 \%(95 \% \mathrm{CI}$ : 73-81) for the BCT group and $71 \%(95 \% \mathrm{CI}: 67-76)$ for the mastectomy group (Fig. 1). After adjustment for age, tumour size and the combined variable of nodal status and adjuvant systemic therapy, the relative risk for recurrence for the BCT group compared to the mastectomy group was $0.96(P=0.75)$ (Table 2). The recurrence risk was halved for node-positive patients who received adjuvant systemic therapy, compared to node-positive patients without adjuvant systemic therapy $(P=0.001)$ (Table 2$)$.

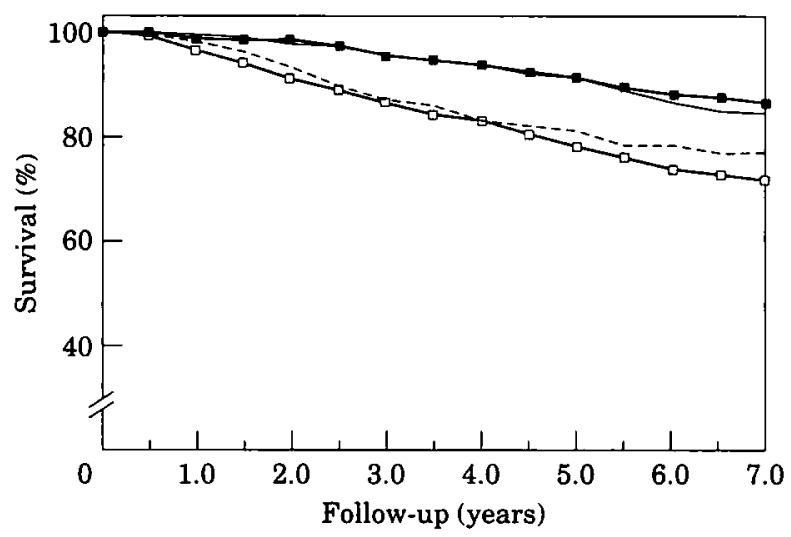

Fig. 1. Life table analysis. Breast cancer-specific survival (BC) and recurrence-free survival (RFS) after breast-conserving therapy (BCT) and mastectomy. $(-=\mathrm{BC}+\mathrm{BCT} ;-\square-=\mathrm{BC}+$ mastectomy; $---=$ RFS + BCT; $-\square-=$ RFS + mastectomy.)

Table 2. Results of multivariate analysis of breast cancer-specific survival and recurrence-free survival $(n=921)$

\begin{tabular}{lcc}
\hline Factor & $\begin{array}{c}\text { Breast cancer- } \\
\text { specific survival } \\
\text { RR (95\% } \\
\text { confidence limit) }\end{array}$ & $\begin{array}{c}\text { Recurrence-free } \\
\text { survival } \\
\text { RR }(95 \% \\
\text { confidence limit) }\end{array}$ \\
\hline $\begin{array}{l}\text { Primary treatment } \\
\text { Mastectomy* }\end{array}$ & 1 & 1 \\
BCT & $1.09(0.74-1.57)$ & $0.96(0.73-1.26)$ \\
Age group (years) & 1 & 1 \\
$\leq 45^{*}$ & $0.77(0.51-1.16)$ & $0.83(0.60-1.13)$ \\
$46-65$ & $0.77(0.45-1.31)$ & $0.64(0.42-0.96)$ \\
$\geq 66$ & 1 & 1 \\
$\begin{array}{l}\text { Tumour size (cm) } \\
\leq 2.0^{*}\end{array}$ & $1.40(0.94-2.06)$ & $1.59(1.19-2.10)$ \\
$2.1-3.0$ & & \\
$\begin{array}{l}\text { Nodal status and } \\
\text { adjuvant systemic } \\
\text { therapy (Adj) }\end{array}$ & & \\
pN, without Adj* & 1 & 1 \\
pN with Adj & $0.48(0.28-0.81)$ & $0.50(0.34-0.73)$ \\
pN $N_{0} \dagger$ & $0.29(0.19-0.44)$ & $0.34(0.25-0.46)$ \\
\hline
\end{tabular}

RR: Relative risk as compared to reference category.

* Reference category; $\dagger$ including nine patients with adjuvant systemic therapy.
Table 3. Site of first recurrence in both treatment groups

\begin{tabular}{lrrrrr}
\hline & \multicolumn{3}{c}{ Primary treatment } \\
\cline { 2 - 3 } & \multicolumn{2}{c}{ BCT } & & \multicolumn{3}{c}{ Mastectomy } \\
\cline { 2 - 3 } \cline { 5 - 6 } Type of first recurrence & \multicolumn{1}{c}{$n$} & $(\%)$ & & $n$ & $(\%)$ \\
\hline Local & 27 & $(26)$ & & 15 & $(13)$ \\
Regional & 9 & $(9)$ & & 13 & $(11)$ \\
Distant & 63 & $(61)$ & & 85 & $(71)$ \\
Local and regional & 1 & $(1)$ & & 2 & $(2)$ \\
Local and distant & 1 & $(1)$ & & 1 & $(1)$ \\
Regional and distant & 3 & $(3)$ & & 3 & $(3)$ \\
Total & 104 & $(100)$ & & 119 & $(100)$ \\
\hline
\end{tabular}

Twenty-seven recurrences occurred in the preserved breast in the BCT group, as the first site of failure, and 15 in the chest wall in the mastectomy group (Table 3). The actuarial local recurrence rates at 7 years were $7.6 \%(95 \% \mathrm{CI}: 4.8-10.4)$ and $5.3 \%(95 \% \mathrm{CI}: 2.9-7.7)$ respectively. Distant metastases developed in 10 of the 27 patients with local recurrence after BCT, and at the time of analysis six of these had died with disseminated disease. Of the 15 patients with chest wall recurrence after mastectomy six developed distant metastases, of whom five died, four with and one without disseminated disease.

\section{Discussion}

Six major prospective randomized trials have now shown equivalent survival in comparisons of breast-conserving surgery and radiotherapy with mastectomy. ${ }^{17-22}$ Our study group was derived from community hospitals, and in contrast to most trial populations older patients were also included. The results indicate that the efficacy achieved in trial centres may be reproduced in routine clinical practice.

We do not think that the non-random assignment of primary treatment has biased our results substantially. To prevent confounding by indication for primary treatment, the study was restricted to patients with a well-defined stage of early breast cancer. The possible confounding effects of age, tumour size, nodal status and adjuvant systemic therapy were eliminated in the multivariate analysis. The smaller proportion of node-positive patients with adjuvant systemic therapy in the mastectomy group is largely explained by the greater proportion of post-menopausal patients in this group and the regional guidelines concerning adjuvant systemic therapy. According to these guidelines postmenopausal patients with an oestrogen receptor-negative tumour were supposed not to receive tamoxifen. During the study period less than $10 \%$ of the post-menopausal patients with an oestrogen receptor-negative tumour received tamoxifen, whereas the proportion of node-positive women with oestrogen receptor-positive tumours increased from $50 \%$ to $80 \%$ between 1984 and $1987 .{ }^{2}$ Currently, tamoxifen is given irrespective of the oestrogen receptor status of the tumour.

Even after multivariate analysis the possibility remains of confounding by factors which have not been documented in the cancer registry. Several relative contraindications for 
the use of BCT, such as the presence of vascular invasion, extensive intraductal component or margin involvement, have not been taken into account, because information was not available at that time. However, these factors may have had only a slight effect on the results. First, patients were diagnosed before 1988, when knowledge of the pathophysiology of local recurrence and many of the risk factors for local recurrence after BCT was still limited. Second, most of the independent risk factors for relapse in the conserved breast are local features, which may not have any prognostic significance for breast cancer-specific survival. And in view of the low local recurrence rate after BCT in this study, local tumour characteristics could only have exerted a small influence on recurrence-free survival.

Though not the central aim of this analysis, we observed a significantly reduced risk of recurrence and death from breast cancer in node-positive patients receiving adjuvant systemic therapy. Such risk reductions are consistent with results from trials. ${ }^{23}$ Numbers were too small to perform a separate analysis of the expected impact of adjuvant systemic therapy on the local recurrence rate..$^{3.24-26}$ Another indirect finding was the better recurrence-free survival of patients $\geq 66$ years compared to patients $\leq 45$ years.

Though based on a non-randomized study, our findings indicate that BCT can be applied adequately in routine practice according to current standards. No significant differences were observed in the breast cancer-specific survival and recurrence-free survival between patients with early breast cancer who were selected for either BCT or mastectomy in the community hospitals in south-eastern Netherlands.

\section{Acknowledgements}

The authors thank W. C. J. Hop (MSc, Erasmus University Rotterdam) for his assistance with statistical methods and Prof J. A. van Dongen (Department of Surgery, Netherlands Cancer Institute) for his comments.

\section{References}

1. Veronesi U, Saccozzi R, Del Vecchio $M$, et al. Comparing radical mastectomy with quadrantectomy, axillary dissection and radiotherapy in patients with small cancers of the breast. $N$ Engl J Med 1981; 305: 6-11.

2. Sarrazin D, Lê M, Rouëssé J, et al. Conservative treatment versus mastectomy in breast cancer tumors with macroscopic diameter of 20 millimeters or less. Cancer 1984; 53: 1209-13.

3. Fisher B, Bauer M, Margolese R, et al. Five-year results of a randomized clinical trial comparing total mastectomy and segmental mastectomy with or without radiation in the treatment of breast cancer. $N$ Engl J Med 1985; 312: 865-73.

4. Butler Nattinger A, Gottlieb MS, Veum J, Yahnke D, Goodwin JS. Geographic variation in the use of breast-conserving treatment for breast cancer. $N$ Engl J Med 1992; 326: 1102-7.

5. Farrow DC, Hunt WC, Samet JM. Geographic variation in the treatment of localized breast cancer. $N$ Engl J Med 1992; 326: 1097-101.

6. Satariano ER, Swanson GM, Moll PP. Nonclinical factors associated with surgery received for treatment of early-stage breast cancer. Am J Public Health 1992; 82: 195-8.

7. Samet JM, Hunt WC, Farrow DC. Determinants of receiving breast-conserving surgery. Cancer 1994; 73: 2344-51.
8. Lazovich DA, White E, Thomas DB, Moe RE. Underutilization of breast-conserving surgery and radiation therapy among women with stage I or II breast cancer. JAMA 199l; 266: 3433-8.

9. Nicolucci A, Mainini F, Penna A, et al. The influence of patient characteristics on the appropriateness of surgical treatment for breast cancer patients. Ann Oncol 1993; 4: 133-40.

10. Chouillet AM, Bell CMJ, Hiscox JG. Management of breast cancer in southeast England. BMJ 1994; 308: 168-71.

11. Nab HW, Voogd AC, Crommelin MA, Kluck HM, van der Heijden LH, Coebergh JWW. Breast cancer in the Southeastern Netherlands 1960-89: trends in incidence and mortality. Eur $J$ Cancer 1993; 29A: 1557-9.

12. Voogd AC, van Beek MWPM, Crommelin MA, Kluck HM, Repelaer van Driel OJ, Coebergh JWW. Management of early breast cancer in South-east Netherlands since 1984: a population-based study. Acta Oncol 1994; 33: 753-7.

13. Voogd AC, Coebergh JWW, Crommelin MA, van der Heijden LH, Kluck HM. Breast-conserving treatment of early breast cancer: survival and recurrence in community hospitals in southeastern Netherlands. Neth J Surg 1991; 43: 105-9.

14. Coebergh JWW, Verhagen-Teulings MTh, Crommelin MA, Masseling E, van der Heijden LH. In: Parkin DM, Muir CS, Whelan SL, Gao YT, Ferlay J, Powell J (eds) Cancer Incidence in Five Continents, Vol. VI. IARC Scientific Publication No. 120, Lyon: International Agency for Research on Cancer, 1992: 666-9.

15. Cutler SJ, Ederer F. Maximum utilization of the life table method in analyzing survival. $J$ Chron Dis 1958; 8: 699-712.

16. Cox DR. Regression models and life tables. J R Stat Soc [B] 1972; 34: 187-220.

17. Blichert-Toft $M$, Brincker $H$, Andersen JA, et al. A Danish randomized trial comparing breast-preserving therapy with mastectomy in mammary carcinoma. Acta Oncol 1988; 27: $671-7$.

18. Veronesi U, Banfi A, Salvadori B, et al. Breast conservation is the treatment of choice in small breast cancer: long-term results of a randomized trial. Eur $J$ Cancer 1990; 26: 668-70.

19. Fisher B, Redmond C, Poisson R, et al. Eight-year results of a randomized clinical trial comparing total mastectomy and lumpectomy with or without irradiation in the treatment of breast cancer. $N$ Engl J Med 1989; 320: 822-8.

20. Sarrazin D, Lè MG, Arriagada R, et al. Ten-year results of a randomized clinical comparing a conservative treatment to mastectomy in early breast cancer. Radiother Oncol 1989; 14: $177-84$.

21. Lichter AS, Lippman ME, Danforth DN, et al. Mastectomy versus breast-conserving therapy in the treatment of stage I and II carcinoma of the breast: a randomized trial at the National Cancer Institute. J Clin Oncol 1992; 10: 976-83.

22. Van Dongen JA, Bartelink H, Fentiman IS, et al. Factors influencing local relapse and survival and results of salvage treatment after breast-conserving therapy in operable breast cancer: EORTC trial 10801, breast conservation compared with mastectomy in TNM stage I and II breast cancer. Eur $J$ Cancer 1992; 28A: 801-5.

23. Early Breast Cancer Trialists' Collaborative Group. Systemic treatment of early breast cancer by hormonal, cytotoxic or immune therapy: 133 randomised trials involving 31000 recurrences and 24000 deaths among 75000 women. Lancet 1992; 339: 1-15, 71-85.

24. Rose MA, Henderson IC, Gelman R, et al. Premenopausal breast cancer patients treated with conservative surgery, radiotherapy and adjuvant chemotherapy have a low risk of local failure. Int J Radiat Oncol Biol Phys 1989; 17: 711-7.

25. Hafity BG, Fischer D, Rose M, Beinfeld M, McKhann C. Prognostic factors for local recurrence in the conservatively treated breast cancer patient: a cautious interpretation of the data. J Clin Oncol 1991; 9: 997-1003.

26. Levine MN, Bramwell V, Abu-Zahra $\mathrm{H}$, et al. The effect of systemic adjuvant chemotherapy on local breast recurrence in node positive breast cancer patients treated by lumpectomy without radiation. $\mathrm{Br} J$ Cancer 1992; 65: 130-2. 